\title{
O PRAGMATISMO CLÁSSICO AMERICANO E A FILOSOFIA DA DIFERENCA: QUESTÕES PARA A EDUCACÃO
}

\section{THE AMERICAN CLASSIC PRAGMATISM AND THE PHILOSOPHY OF DIFFERENCE: ISSUES FOR EDUCATION}

Solange Puntel Mostafa Doutorado em Educação: História, Política, Sociedade pela PUC/SP.

Faculdade de Filosofia, Ciências e Letras de Ribeirão Preto Universidade de São Paulo (USP)

Ribeirão Preto - SP - Brasil

Endereço:

Av. Bandeirantes, 3900 Monte Alegre - Ribeirao Preto - SP

CEP: $88306-120$

E-mail:

smostafa@terra.com.br

\section{RESUMO}

Desenvolve as ideias dos pragmatistas americanos clássicos como William James e John Dewey em seus conceitos principais de empirismo radical, experiência, experiência pura e educação, aproximando-as dos conceitos filosóficos pensados por Gilles Deleuze e Félix Guattari; tal aproximação permite demonstrar o plano estratigráfico da filosofia e a sua importância para o campo educacional.

PALAVRAS-CHAVE: William James. John Dewey. Gilles Deleuze. Pragmatismo.

ABSTRACT

It develops the ideas of classic american pragmatists like William James and John Dewey in its main concepts of radical empiricism, experience, education and pure experience; such ideas are put together with the philosophical concepts thought by Gilles Deleuze and Félix Guattari to demonstrate the stratigraphic plan of philosophy and its importance to the field of education.

KEY WORDS: William James. John Dewey. Gilles Deleuze. Pragmatism.

\section{INTRODUÇÃO}

O pragmatismo pode ser pensado como uma escola de pensamento filosófico americana, em cujo contexto desenvolve-se a filosofia de três pensadores: Charles S. Peirce (1839-1914), William James (1842-1910) e John Dewey (1859-1952). Como a aproximação entre Deleuze e Peirce foi alvo de atenção da autora em outra oportunidade, este artigo objetiva explorar as ideias de Dewey e de James com relação à filosofia da diferença praticada por Gilles Deleuze e Félix Guattari. De todos esses pensadores mencionados, apenas John Dewey dedicou-se especificamente aos processos 
educacionais; Peirce desenvolve compreensões sobre a percepção humana com a teoria dos signos e James falará em experiência radical que podemos traduzir pelo 'plano de imanência' presente em Deleuze e Guattari.

Dos três pragmatistas americanos, Deleuze (e Guattari) dedicam-se mais aos escritos de James e Peirce, esse último com capítulo inteiramente dedicado aos signos no livro de Cinema II, assinado por Deleuze. Mas as ideias deleuze-guattarianas aproximam-se também das ideias de John Dewey, tendo esta aproximação merecido análise original de Semetsky (2006) em título também original, ao relacionar o filósofo francês com a educação e o devir.

O termo "pragmatismo" é produtivo na medida em que remete à praticidade, interesses e resultados. Entretanto, o senso comum residual deixado pelas abordagens dialético-marxistas, deu ao pragmatismo uma conotação política de abordagem pouco profunda, superficial ou interesseira. Filósofos como Rorthy, tido como neo-pragmatista, atribui tais desconsiderações aos filósofos europeus, que nunca acreditaram ser a colônia americana produtora de um pensamento filosófico, a não ser de um pensamento "de curto prazo". Descartes e seu cogito (1596-1650) é um dos principais focos de reconstrução no pensamento pragmatista americano, pois o cartesianismo influencia toda a filosofia ocidental desde o século XVII. Deleuze também vai dedicar boas páginas à identificação do pensamento cartesiano como uma imagem dogmática do pensamento. Pois sua fórmula é "todo mundo sabe...", todo mundo sabe o que significa pensar (DELEUZE, 2006, p. 190). Eu penso! É o idiota de Descartes, o homem que pensa sem pressupostos. Na verdade pressupõe formas privadas de pensar e não públicas, bem como pressupõe que o pensamento nos ocorre naturalmente, o que permite à Filosofia parecer começar e recomeçar sem pressupostos. Os pragmatistas clássicos foram bastante influenciados por Darwin, que os ajudou a criticar o cartesianismo. Descartes pensou o conhecimento como algo a ser obtido por meio das ideias, e as ideias como sendo objetos de pensamento na mente individual; os objetos de pensamento são imagens pictóricas que refletem o mundo lá fora. Reside aí a questão clássica da representação. As ideias representam as coisas e o mundo. Esta visão representativa do conhecimento fez da epistemologia uma das correntes centrais na filosofia. Descartes é por isso considerado um dos pais do fundacionalismo. Mas quase toda a filosofia ocidental europeia, dita continental, pressupõe verdades ou fundamentos para a cognição e para esta relação do homem com o mundo que podem ser consideradas fundamentalistas. As ideias são como espelho da natureza, daí o título do livro de Rorty ${ }^{1}$ "A filosofia e o espelho da natureza" (1995).

\section{O PRAGMATISMO DE JOHN DEWEY}

Rejeitar o idealismo cartesiano não significou para os pragmatistas clássicos abraçar o empirismo inglês, tal como ele se apresenta na obra de Bacon (1561-1626) ou de Hume (1711-1776), pois isto representava também uma teoria correspondentista da verdade. Dewey, inclusive, refere-se a esta teoria do conhecimento como especular, uma vez que ela supõe a existência do conhecimento em algum lugar para ser expectado ou descoberto. Para rejeitar essa noção, os pragmatistas entendem os seres humanos como animais na inspiração darwiniana, e animais em interação com o meio ambiente. O conhecimento surge como resultado desta interação e, portanto, não tendo nenhum valor intrínseco, como supõe a visão representacionista cartesiana.

O conhecimento é parte do viver. Viver é conhecer. Mas não se trata de adaptação ao meio. Trata-se de criação de um espaço relacional entre os vivos, sem nunca deixar de considerá-los, natureza. A linguagem surge como modos de interação, orientação de conduta e [... ainda que primitivamente se dê entre seres orgânicos, inclui coisas energias externas às criaturas vivas".] (DEWEY, 1979 p. 201).

Com o exemplo do apito do guarda, Dewey ilustra o conhecimento como resultado da interação do homem e o ambiente: a lógica do significado do apito não está apartada das normas consensuadas, social e naturalmente. Crenças não são hábitos momentâneos da consciência e sim hábitos duráveis que impulsionam à ação. Portanto, significado, coerência, lógica, tudo isso está, no pragmatismo, subordinado ou condicionado à experiência do vivido. Vida é a um só tempo, natural e social. Aliás, a separação entre natureza e sociedade, sujeito e objeto são as grandes dicotomias, inauguradas por Descartes na modernidade, e que o pragmatismo tentará superar. 
Dewey desenvolve uma "Lógica" da Investigação, isto é, interessar-se-á justamente pelo processo que a epistemologia já dá como pronto. E entenderá que há também uma lógica que comanda o processo investigativo. As crenças no pragmatismo são sempre consideradas em relação às consequências práticas que elas produzem ou dão como efeito (e não lógicas). As ideias no pragmatismo não são verdadeiras nem falsas, pois elas não correspondem ao estado de coisas, tidas como fixas, de uma vez por todas. O mundo dos objetos e dos sujeitos é um mundo em variação contínua, como diria Bergson, o filósofo europeu, de quem James era amigo e correspondente. A verdade de uma ideia depende se ela faz alguma diferença na vida prática de alguém; as ideias são ferramentas de por o mundo em movimento.

Quando Dewey descreve a teoria do método empírico em filosofia, elabora perguntas que lembram as cláusulas deleuze-guattarianas para a filosofia, no enfrentamento com a não filosofia. Dewey fala mesmo num teste de primeira ordem a que toda filosofia teria que se submeter (DEWEY, 1974 p. 167):

- Tal filosofia produz conclusões para nossa vida, tornando-a mais significativa ou ao contrário deixa as coisas mais confusas ou opacas?

- Enriquece a nossa vida ordinária tanto quanto os achados da ciência ou se coloca em um lugar técnico inacessível, afastando da filosofia das pessoas razoáveis?

Entende também Dewey (1974) da necessidade de ilustrar o método empírico da filosofia com a noção de experiência que para ele é quase encontro de corpos (se quisermos lembrar Espinosa), senão, vejamos: a experiência inclui tudo aquilo que os homens fazem e sofrem, mas também como eles fazem, as "maneiras pelas quais eles realizam e padecem, desejam e desfrutam, vêem, crêem, imaginam - em suma, processos de experienciar" (DEWEY, 1974, p. 168). Dewey prossegue dizendo que: "experiência designa o campo plantado... as searas ceifadas, as alternâncias entre dia e noite ..., designa também aquela planta ..." (idem)

Depois de descrever os sentimentos "daquele que planta" e que "se alegra, espera, teme, planeja, invoca a magia ou a química em busca de auxílio...", Dewey esclarece que a experiência é de "duplo sentido", não admitindo divisão entre ato, sujeito e objeto. Citando James, diz que a experiência supõe coisa e pensamento num sentido único, no qual organismo e ambiência acham-se incluídos. No texto sobre a lógica, o autor secundariza a questão do conhecimento, consoante todos os empirismos, para os quais vale mais o processo de conhecer do que o próprio produto; mas não só: é que os processos gnosiológicos, no empirismo, desde o empirismo clássico de David Hume no século dezoito, até o empirismo deweyniano do século XX são processos permeados pela imaginação, emoção e interação com o ambiente. Daí Dewey perceber a ambiência como constituída pelas ações mútuas entre coisas e um ser vivo. Um palco de ações efetuadas e de consequências sofridas em processos de ação recíproca; só secundariamente, partes e aspectos da mesma tornam-se objetos de conhecimento; seus componentes são, antes de tudo, objetos de uso e de gozo-sofrimento, não de conhecimento.

Há um toque espinosista neste conceito de experiência deweyniano e lembra os dois atributos (pensamento e extensão) da substancia infinita de Espinosa e seus infinitos modos, senão vejamos as afirmações de Dewey: "o universo é um conjunto infinito de elementos, que se relacionam de maneira a mais diversa possível. A multiplicidade e variedade dessas relações o fazem essencialmente precário, instável, e o obrigam a perpétua transformação". Segue Dewey: "Pode-se mesmo dizer que tudo existe em função dessas relações mútuas, pelas quais, os corpos agem uns sobre os outros, modificando-se reciprocamente" (DEWEY, 1975, p. 13).

Dewey conclui a definição de experiência dizendo que é "esse agir sobre outro corpo e sofrer de outro corpo uma reação é, em seus próprios temos", a experiência.

Acrescenta algo importante: a experiência não é um atributo puramente humano, mas diz respeito a todos os corpos, uns com os outros. E o que há de fundamental, esclarece Dewey, nesta maneira de entender a experiência, é a sua identificação com a natureza. A experiência é um modo de existência da natureza.

É impossível não associar, na leitura desses filósofos pragmatistas, as posições também desenvolvidas pela filosofia da diferença de Gilles Deleuze e Félix Guattari, ela própria também eivada de espinosismo. O conceito de plano de imanência deleuze-guattariano e o conceito de experiência pura de William James fazem coro com essas imagens que Dewey nos traz, sobre a inteireza inclusiva da experiência. 
O método empírico da filosofia proposto por Dewey é assim o único método capaz, segundo ele, de fazer justiça a essa inteireza inclusiva da experiência. Só este método toma essa unidade integrada como o ponto de partida para o pensamento filosófico. Dewey afirma, ainda, que o método empírico da filosofia tem que observar e explicar como e por que o todo, em outras filosofias, erroneamente separado em Sujeito e Objeto, natureza e operações mentais e como se dá essa separação.

Comenta ainda que Kant separou essas duas instâncias e por causa disto é que teve que enfrentar o problema de como é possível o conhecimento. Já a teoria da investigação deweyniana resolve problemas a partir da experimentação. Uma situação problemática cujo estado das coisas é indeterminado e precisa de análise do pensamento; se há em Dewey uma inspiração espinosista, o pensamento é a própria natureza, pois é um dos atributos da substância infinita de Espinosa.

O pensamento pensa a situação problemática, formula um curso de ação baseado nesta análise, caminhando para a situação determinada, em que a pessoa coexiste com agora, um novo e desenvolvido ambiente. Dewey não restringe seu método empírico de filosofia a questões científicas; o método proposto é um método de resolver problemas gerais da existência. Da mesma forma que James, Dewey professaria um "relativismo objetivista", no qual as coisas do mundo têm sentido de acordo com nossas experiências prévias, interesses e objetivos. Também está de acordo com James em seu entendimento de que as crenças são instrumentais; aplicadas a nossa experiência, são capazes de gerar novo conhecimento.

\section{JOHN DEWEY E GILLES DELEUZE}

Aqui novamente salta a vista o pensamento deleuziano, quando Dewey sustenta, também de acordo com James, que o ato de aprender é um ato inerentemente criativo. $O$ ato inventivo e a criação de conceitos são também centrais na filosofia da diferença deleuziana. Deleuze e Guattari não param de dizer que os conceitos filosóficos não estão prontos para que nos apropriemos deles; eles precisam ser criados e, só eles, como conceitos filosóficos, são capazes de mudar o mundo de maneira absoluta.

Aliás, os autores declaram no livro testamento chamado O que é filosofia (1997) que a tarefa da filosofia é exatamente esta, a criação ou a invenção de conceitos. Nisto consiste a experimentação para Deleuze e Guatarri. Experimentar é viver. Filosofar é experimentar, até porque, fora da lógica formal, o conceito não tem por função representar o mundo, mas inventar novos mundos possíveis. O que só pode ser realizado no processo experimental do ajuste, do risco, do salto. "Pensar é experimentar mas a experimentação é sempre o que se está fazendo - o novo, o notável, o interessante substituem a ...verdade e são mais exigentes do que ela" (idem, p. 143). A filosofia, com seus conceitos, faz os movimentos absolutos do pensamento. É ela que propõe novas ordenadas cartográficas, latitudes e longitudes que traçamos sobre a terra. Somos, sobre a terra, como lagostas que se põem a andar em fila no fundo da água e a terra, ela própria, se confunde com nossos movimentos. Nós, peregrinos em busca de linhas de fuga, de novas imagens do pensamento. Um "pensar (que) se faz antes na relação entre o território e a terra" (DELEUZE; GUATTARI, 1997, p. 113). A arte, com seus perceptos e afectos, por meio de suas figuras estéticas, provoca sensações compostas, fixa o caos em seus monumentos; a ciência, com seus observadores parciais, por intermédio de funções e proposições, traça suas referências e a filosofia, dentro de seu plano de imanência, pelos seus personagens conceituais, cria sempre novos conceitos e imagens do pensamento. A maneira como os filósofos franceses apresentam Filosofia é uma maneira revolucionária, pois colocam as três grandes formas do pensamento em posição hierarquicamente igual. Não há proeminência nem privilégios de uma maneira de pensar sobre a outra. Entretanto, cada uma delas tem, agora, suas atribuições, seus indivíduos, suas funções, suas possibilidades, seus devires e seus limites.

Encontraremos Dewey (1974) defendendo esta mesma posição de paridade entre processos intelectuais e artísticos, no texto sobre a arte e a experiência, embora de maneira en passant. Deleuze e Guattari confessam estarem escrevendo um livro inteiramente dedicado ao tema da filosofia e suas relações com a arte e a ciência, por ser a bibliografia escassa. Mais do que isso, por estarem na velhice e ter chegado a hora de falar mais concretamente: "Simplesmente chegou a hora para nós de perguntar o que é filosofia" (DELEUZE; GUATTARI, 1997, p. 10). Deleuze e Guattari, em sua teorização, dão vida nova à filosofia que, por muitas vezes, esteve condenada a desaparecer, 
fulgurada pela importância demasiada dada à ciência ou à arte e, também, pelas atitudes dos próprios filósofos. Alguns deles que, ao esquecer ou não reconhecer esse papel da filosofia, se contentaram, por muitos anos, em fazer o que, certamente, não é Filosofia: contemplar, refletir e comunicar. Para Deleuze e Guattari, a filosofia não pode ser contemplação, porque isso significa a coisa, ela mesma, vista da ótica de sua própria criação. Em relação à reflexão, a argumentação é mais complexa, porque, por muito tempo, é tudo o que tem sido feito em termos de filosofia pela maior parte dos "filósofos". Como dizem Deleuze e Guattari, quem precisa de quem para refletir sobre alguma coisa? Reflexão, por exemplo, na filosofia da educação, significa educadores refletindo sobre sua própria criação (a educação) e não preocupados com a criação de novos conceitos filosóficos como novas imagens de pensamento para a educação. Por fim, filosofia não é comunicação: a comunicação é aquela disciplina que tem a opinião em potência e, portanto, está preocupada com o consenso, com a sua aplicação democrática. Em última análise, a comunicação preocupa-se com o universal, com uma verdade construída, uma ilusão de dominação das outras formas de pensar.

A filosofia, ao contrário do universal, do consenso ou da doxa, opera por singularidades. A criação dos conceitos filosóficos tem como finalidade explicar o que os tais universais não explicam. É certo o comprometimento da filosofia com o estranhamento, com a desbanalização do que aparentemente é sem importância, com o espantar-se diante da vida, mas insistimos com Deleuze e Guattari, o importante é fazer filosofia por meio do conhecimento trazido pela criação dos puros conceitos. A recusa ao universalismo é uma marca de todos os pragmatismos, inclusive o dos filósofos franceses. Dewey, por sua vez, ataca duramente o subjetivismo filosófico representado pela filosofia de Descartes, mas também ataca o intelectualismo do empirismo clássico de Locke, Hume ou Espinosa. Recusa o dualismo entre matéria e mente trazido por essas filosofias, como resultado de abandonar a experiência bruta. Propõe para tal a integração ou agregação de ambos, objetos físicos e mentais.

Apesar de propor o método filosófico baseado no desenvolvimento da ciência, ao enaltecer o teste dos resultados científicos no retorno à experiência primária, Dewey (1974, p. 163) enaltece também a poesia e as artes, que no seu entender, são tão importantes quanto a filosofia (idem, p. 174). Critica o intelectualismo na filosofia ao transformar toda a natureza em objeto de conhecimento científico e apenas científico, não deixando espaço para o gozo e a fruição (idem, p. 175). O problema passa a ser então como e por que a filosofia intelectualista secundariza os traços afetivos e volitivos [afeto e desejo] na experiência primária, já que a experiência primária é um movimento de ação e paixão (idem, p. 176). O conhecimento só serve, diz Dewey, para administrar o fazer e o padecer, que, juntos, constitui a experiência. Experimentar não é simplesmente fazer alguma coisa, mas é fazer de tal modo que se possa fazer de outro modo (mais rico, mais completo, mais inclusivo) (idem, p. 167).

Nas palavras do próprio Dewey: "Um homem faz algo; levanta a pedra... em conseqüência, padece, sofre alguma coisa: o peso, a resistência, a textura da superfície da coisa levantada..". (idem, p. 253). Uma adaptação mútua ocorre entre o eu e o objeto até que a experiência chegue ao final. Ação e consequência (fazer e padecer) precisam estar juntas na percepção. Com esta compreensão, Dewey discorre sobre a arte como experiência e aqui também, seu pensamento se aproxima dos filósofos franceses Deleuze e Guattari, em alguns aspectos: a criatividade na recepção da obra de arte (o espectador tem que criar sua própria experiência), a arte é também pensamento e exige pensar com o mesmo rigor de quando se pensa por meio de símbolos verbais e matemáticos exigidos na ciência. É interessante notar as várias apropriações que o texto Arte como experiência teve no Brasil, com relação ao ensino da arte-educação nas escolas brasileiras, como relatado por Barbosa (2008). Chama a atenção, no relato da autora, o desconhecimento do texto entre os educadores brasileiros idealizadores da Escola. Mas toda a filosofia Deleuze-guattariana é uma pedagogia do conceito (portanto uma forma de ensino da filosofia), mas o que mais vale destacar, neste cotejo, são as inovações deleuzianas para as imagens em que o cineasta ou o pintor torna-se um vidente, um visionário na medida em que vê e faz ver coisas com o pensamento, no método do 'entre'. Cogito se John Dewey não estaria dizendo coisa semelhante, quando teoriza sobre o processo de criação da obra de arte, que para ser verdadeiramente artística, precisa incorporar a estética, isto é, a fruição, a fim de surgir o sentido entre as imagens. Fruição do próprio artista, enquanto trabalha.

Os três momentos preconizados por Dewey no texto Arte como experiência (fazer artístico, apreciação e contextualização) compõem a metodologia triangular da arte-educação no Brasil e, com efeito, já fazem parte dos parâmetros curriculares há algum tempo: a criança da escola brasileira 
desenha, aprecia o desenho dos colegas no varal e se tiver sorte de um bom professor, contextualiza um Abaporu no modernismo brasileiro paulista. Por último, cabe destacar uma característica do pragmatismo de Dewey (1974, p. 175) que o aproxima bastante de Deleuze e Guattari, quando Dewey atesta uma névoa de virtualidade cercando o real e os objetos da natureza ("o escuro e o crepuscular são abundantes na natureza"). Para Dewey, é importante para a filosofia lidar com isso até porque isto tipifica uma questão ontológica da relação entre as ideias e as coisas. O campo transcendental (virtual) é tão importante para Deleuze e Guattari quanto para os pragmatistas.

Tudo o que existe, existe também como ideia. Existe a cadeira e a ideia de cadeira. Cada coisa do mundo real possui a sua ideia. A cadeira precisou ser idealizada para ser cadeira. Mas onde se aloja a ideia de cadeira? No pensamento humano? Entretanto a árvore também realiza a ideia de árvore. O Pensamento para Deleuze e também para os pragmatistas não é atributo exclusivo dos seres humanos. Há pensamento na natureza. Natureza-Ser, natureza-pensamento. Para Deleuze e Guattari, a Ideia também é o princípio último do mundo, razão suficiente do seu ser e de sua gênese. Mas ela não se opõe às coisas, pois ela lhes é imanente. As coisas e as ideias não estão tão distantes como se estivessem habitando dois mundos distintos, a exemplo de Platão: o mundo das ideias separado do mundo sensível.

Na filosofia empírica e imanente, existe um e apenas um mundo; as ideias são imanentes às coisas (e não transcendentes). É um mundo só (imanência!). Mas esse mundo é composto de atuais e virtuais. Todas as ideias estão implicadas, de modo virtual, na Ideia-Ser. As ideias existem como tendências no plano de imanência, que é virtual. Virtual implica virtus, isto é, eficiência de tornar-se atual no processo que Deleuze chama de diferenciação. As ideias são virtualidades puras e de modo algum se assemelham ao atual. Nem semelhança, nem similitude para não cairmos na concepção de ideia como representação do mundo. A ideia é a coisa, no sentido que lhe corresponde, mas Deleuze adverte que é uma correspondência sem semelhança; "[...] A idéia se atualiza por diferençação. Para ela atualizar-se é diferençar-se" (DELEUZE, 2006, p. 386). Assim, Deleuze reconhece que só o empirismo sabe como transcender ou ultrapassar a dimensão experimental ou empírica do visível, sem cair nas ideias transcendentais de Platão ou Kant. Por isso, a sua admiração por David Hume, cuja filosofia é anterior a Kant, bem como a sua admiração pelo pragmatismo americano clássico.

\section{O PRAGMATISMO DE WILLIAM JAMES}

Dentre os três filósofos americanos, James é o responsável em retomar o conceito original de Peirce sobre o pragmatismo como doutrina. Comenta em sua II Conferência que o termo deriva da palavra "pragma que significa ação", tendo sido usado a primeira vez por Charles Peirce em 1878, o qual dizia que nossas crenças são regras de ação.

Ressalta que, para Peirce, como para ele, o significado de um pensamento está na conduta por ele desencadeada: "aquilo é para nós o seu único significado" (JAMES, 1974, p. 10). Segundo James, essa compreensão do pragmatismo originária em Peirce esteve esquecida por vinte anos, até que ele, em reunião acadêmica de 1898, fez notar tal especificidade e, a partir daí, a noção e o sintagma "pragmatismo" ganharam abrangência.

James reivindica uma nova visão do mundo, confrontada com novos conceitos que lhe permitiram cunhar a expressão empirismo radical. "Para ser radical, um empirismo não deve nem admitir em suas construções qualquer elemento que não seja diretamente experenciado" (JAMES, 1979, p. 188). Importante também é seu conceito de experiência pura como campo instantâneo do presente (JAMES, idem, p. 181).

Assim, até as relações devem fazer parte da experiência, sendo que toda e qualquer relação experienciada significa algo tão real quanto os dados experenciados. James julga o empirismo de Hume insuficiente por ele falar em disjunção entre impressões e ideias, ao passo que James entende tratar-se de relações conjuntivas, como se nossas percepções se prolongassem nos objetos lá fora.

Quase parafraseando James, o filósofo francês Gilles Deleuze, no prefácio da edição inglesa dos Diálogos, também se diz empirista: "sempre senti que sou um empirista, isto é um pluralista. Um pluralista assume que o abstrato ou o universal não explica nada, pelo contrário, é o que precisa ser explicado. E explicado de tal maneira a encontrar condições que permitam a produção 
do novo" (DELEUZE apud BELL, 2009, p. 1). Essas condições de produção, para o filósofo Deleuze, não são sociais, mas representam forças de contra-efetuação da história ou do vivido. São forças intuitivas e a-históricas as forças que permitem atingir o campo transcendental, que é o que interessa ao seu empirismo.

James discorre, portanto, sobre a verdade no pragmatismo, trazendo os novos conceitos de empirismo radical e experiência pura. Sua proximidade com o filósofo francês Henri Bergson o faz pensar também no conceito de duração e de multiplicidades intensivas, bem como nos conceitos filosóficos de reconhecimento automático e reconhecimento atento, aquele que abre mão do prolongamento sensório motor e cria outra imagem, em outros planos, em outro tempo, retendo dos objetos percebidos, apenas alguns traços.

O conhecimento humano e a atividade realizada ou intencionada são informados pelos interesses e objetivos que portamos em nosso encontro com o ambiente. "Não há propriedades absolutamente essenciais em nada... a essência de uma coisa é uma de suas propriedades que é tão importante para meus interesses, que negligencio o resto".

James entende que toda a história da filosofia tratou o sujeito e o objeto como entidades descontínuas e que caberia ao pragmatismo entender as continuidades em nossa percepção, pois só assim, por meio dessas transições sentidas, é que alcançaremos conhecimento. "O conhecimento das realidades sensíveis vem à luz no tecido da experiência" (JAMES, 1974, p. 121).

James entende o pensamento como um fluxo. Mais do que nunca ele está interessado no contexto da descoberta, aspecto que não interessa à Epistemologia. Em resposta à pergunta "como acontece o pensamento", James delineia cinco características em seus princípios de Psicologia (JAMES, 1974, 49-50):

- Todo pensamento tende a ser parte de uma consciência pessoal;

- Dentro de cada consciência pessoal, o pensamento está sempre mudando;

- Dentro de cada consciência pessoal, o pensamento é sensivelmente contínuo;

- Ele sempre parece lidar com objetos independente de si próprio;

- Ele está interessado em algumas partes desses objetos com exclusão de outras partes, e acolhe ou rejeita - escolhe, dentre elas, em uma palavra - o tempo todo.

Mas há também em James o campo instantâneo do presente que é seu conceito de experiência pura, pré-subjetiva e ainda sem consciência. É neste campo, que tanto em James quanto em Deleuze vai aparecer a ideia do virtual ou das realidades pré-pessoais. Deleuze identificará a imanência pura nesse campo. James assim explica o seu conceito: "Experiência pura é o nome que dei ao fluxo imediato de vida que fornece o material à nossa reflexão posterior com suas categorias conceituais... aquilo que não é ainda um o quê definido, apesar de poder ser todas as espécies de o quês" (JAMES, 1974, p. 134).

\section{WILLIAM JAMES E GILLES DELEUZE}

Como a imanência é um conceito fundamental na filosofia da diferença deleuziana, pareceunos importante relacioná-la à experiência pura de James. Apenas para completar a ideia da filosofia pensada por Deleuze, haverá o plano de imanência em paralelismo com a construção dos conceitos filosóficos. Na leitura de Deleuze e Guattari, é definido um plano de imanência radical, completo, sem possibilidades para a transcendência e este plano está ligado ao nome de Espinosa (16321677). Justamente porque Espinosa pensou em um e apenas um mundo. Mas entendemos que o plano de imanência deleuze-guattariano pode ser relacionado à experiência pura jamesiana, sem o menor temor de perdas.

Deleuze e Guattari entendem a filosofia como um construtivismo, pois tanto os conceitos precisam ser criados, como o plano precisa ser instaurado. Os autores explicam-nos, didaticamente, o que seria esse plano, esse Uno-Todo ilimitado que abriga os conceitos, essa curvatura variável, deserto a ser povoado por eles, essa imagem do pensamento que, por sempre ter estado lá, sem ser pensável, nem pensada, dá os traços diagramáticos para que os conceitos, como dimensões 
absolutas, ou intensões (assim mesmo, grafado com "s", significando intensidades), se organizem em uma nova maneira, numa nova imagem de pensamento.

É importante que se diga aqui, mais uma vez, para deixar sempre clara, a intenção dos autores de explicar a filosofia com seus conceitos criados, com o plano de imanência instaurado como um plano de consistência para esses conceitos, por meio da invenção de personagens conceituais que se movimentam sobre territórios e sobre a terra, para falar sobre Acontecimentos. Todos os capítulos do livro $O$ que é a Filosofia? de Deleuze e Guattari soam e ressoam uns nos outros com a finalidade didática, ou pedagógica, de demonstrar que os pensamentos-conceitos estão colocados em um plano de consistência pragmático, de experimentação.

A aproximação entre James e Deleuze pode ser percebida também quando Deleuze afirma serem os americanos os inventores da colcha de retalho ou do patchwork como princípio de conhecer o mundo. Isto está expresso não apenas na literatura e na poesia americanas, mas na própria filosofia pragmatista.

Se a literatura americana identificada por Deleuze, na experiência do território americano com seus movimentos migratórios, traz as características deste desbravamento, a filosofia correspondente de William James vai falar em deambulação. Deambular não significa que o conhecimento esteja submetido à errância, mas que ele se faz pouco a pouco, por meio de junções sucessivas: "Nosso conhecimento cresce por pontos" (JAMES, 1979, p. 60).

Os pontos podem ser pequenos ou grandes, mas o conhecimento jamais cresce por inteiro: "algum conhecimento antigo sempre permanece o que foi" (idem). É Deleuze que vai destacar, então, a característica de patchwork do pragmatismo americano: "[...] os americanos inventaram a colcha de retalho, no mesmo sentido em que se diz que os suíços inventaram o cuco" (DELEUZE apud LAPOUJADE, 2000, p. 274). O conhecimento consiste em construir um patchwork numa tecitura em pedaços.

A constituição da nação americana em sua condição fragmentária faz Deleuze entendê-la como um mundo em arquipélago, em que uma comunidade de exploradores irmanados substitui o conhecimento pela crença e pela confiança. Sociedade de irmãos. Para que esta comunidade seja possível, o conhecimento e a verdade passam a ser uma questão de confiança e de crença. Dirá Deleuze que não entenderemos o pragmatismo americano se o classificarmos como uma filosofia sumária ou utilitarista, base da economia capitalista, como fez a crítica europeia, a partir do seu ponto de vista dialético-marxista.

O migrante americano, autor desta literatura e criador desta filosofia, percorre um tempo entre as primeiras comunidades de pioneiros e a expansão da industrialização, portanto está situado entre 1850 e 1920, o que os faz mais itinerantes do que homens de negócio, participando do capitalismo americano de uma maneira muito particular, na exploração do território, na construção de estradas e de paradas provisórias, a modo de um arquipélago. São operários nômades, distantes dos sindicatos, nos movimentos demissionários da economia capitalista que os força a deambular, a seguir na grande estrada. Por isso a noção de patchwork na filosofia de William James permite pensar não apenas o conhecimento, mas o mundo como um sistema de redes, antecipando as redes de comunicação contemporâneas: patchworks e networks são relações construídas passo a passo, pedaço por pedaço, como um grande tecido que não se fecha, porque sempre aberto a novas relações e novas associações.

James fala então de uma filosofia em mosaico: "Nós mesmos criamos constantemente conexões novas entre as coisas, organizando grupo de trabalhadores, estabelecendo si temas postais,... rede de vias férreas... que nos relacionam e nos unem por meio de uma rede cuja amplitude se estende..." (JAMES apud LAPOUJADE, 2000, p. 274-5).

Pois bem, essa constituição fragmentária do conhecimento e do mundo não pode obscurecer o plano de imanência de uma experiência pura na qual estamos desde sempre mergulhados, antes de sermos sujeito e objeto; pois para ser empirista radical, é preciso considerar a experiência de um ponto de vista amplo, em que as coisas entrem em relação, sem que se tenha consciência desta relação, como se pudéssemos regredir a uma condição larvar para entrar em relação com os outros seres do Universo. 
O plano de imanência age como um crivo no caos, explicam Deleuze e Guattari (2005, p. 59); o caos não é um estado inerte ou uma mistura ao acaso; o plano de imanência é ao mesmo tempo o que deve ser pensado e o que não pode ser pensado e tem duas faces: como pensamento e como natureza, como physis e como nous ${ }^{2}$. Este campo transcendental da experiência pura jamesiana ou do plano de imanência deleuziano é um campo já percorrido por relações como um tecido é percorrido por fibras ou linhas. 'Gigantesco tear', dirão Deleuze e Guattari, já que o plano não para de se tecer. Plano de virtualidades puras, caos das relações possíveis e virtuais; o virtual é a condição transcendental de toda experiência.

E para ser empirista radical, na concepção de William James, é preciso abrir mão dos Universais, pois só os particulares existem na vida real, mas também é preciso acessar este campo virtual, que envolve o real, mas que não se traduz em universalismos. Antes se traduz por multiplicidades, que é o terceiro princípio do rizoma deleuzo-guatarriano. Uma multiplicidade de atuais e de virtuais. Pois a todo atual corresponde um virtual. É uma correspondência sem semelhança, em que o virtual em nada se parece com o atual.

Ao aproximarmos Dewey, James, Deleuze e Guattari, filósofos de séculos diferentes, o que fazemos é colocá-los em um mesmo plano de imanência, dada a proximidade dos conceitos filosóficos que criaram (experiência pura e plano de imanência), no tempo estratigráfico da filosofia. Deleuze define a sua filosofia como uma teoria das multiplicidades, da mesma maneira que James identifica o seu pragmatismo ou empirismo radical a uma filosofia de mosaico. Em outra oportunidade, trouxemos a este mesmo plano, empirista e radical, David Hume, pois, desde que considerada a leitura deleuziana de Hume, essa aproximação é possível (MOSTAFA, 2010).

Este plano de imanência pré-subjetivo e pré-individual apresenta apenas acontecimentos ou mundo possíveis como conceitos, visto que o conceito nessas filosofias empíricas radicais não é cópia das coisas, não é representativo. Outrem, como 'mundo possível' é um conceito filosófico criado por Deleuze e Guattari justamente para mostrar que não há sujeitos ou objetos neste plano genético e cosmológico, mas apenas relações e são elas que fazem o mundo passar (MOSTAFA; NOVA CRUZ, 2009). O mundo passa por meio das experiências que se dão no real, com ou sem a intervenção dos sujeitos. Em James, a experiência é identificada à vivência de criar um percurso e seguir as linhas virtuais deste percurso, por junções sucessivas, por pedaços que se agrupam - por deambulação. Percepções, pensamentos ou emoções são tratados como pedaços ou como fragmentos. Quando Deleuze e Guattari (1997, p. 72) descrevem o plano de imanência, denunciando as ilusões que costumam permear o plano (por ex. a ilusão da transcendência; a ilusão dos universais, do eterno e da discursividade), afirmam ser o empirismo do século XVIII o único plano de pensamento capaz de afastar essas ilusões. Pois o empirismo substitui o conhecimento pela crença, na criação de grandes conceitos como associação, relação, hábito, probabilidade e convenção.

\section{CONSIDERAÇÕES FINAIS}

John Dewey é um filósofo pragmatista que dispensa apresentação no campo educacional brasileiro, tal a profusão de trabalhos versando sobre sua filosofia da educação. Peirce talvez tenha tido mais penetração no campo da comunicação com suas explicações de como percebemos o mundo por meio dos signos. E William James é um autor mais próximo da área de psicologia com a noção de empirismo radical. Deleuze e Guattari são filósofos transversais a várias áreas, como literatura, cinema, arte e educação. Separados, todos esses filósofos já mereceram análises em cada uma dessas áreas específicas. Nosso esforço neste artigo foi reuni-los para aproximá-los em um mesmo plano, nem sempre tão visível, de modo a percebermos o tempo estratigráfico da filosofia e as fertilizações possíveis para o campo educacional.

\section{REFERÊNCIAS}

BELL, J. A. Deleuze's Hume; philosophy, culture and the Scottish enlightenmt. Edinburgh University Press, 2009.

DELEUZE, G. Crítica e clínica. São Paulo, Ed. 34, 1997. 
DELEUZE, G. O atual e o virtual. IN: ALLIEZ, E. Deleuze, filosofia virtual. São Paulo: Ed. 34, 1996. p. 47-56.

DELEUZE, G. GUATTARI, F. O que é a filosofia? São Paulo: Ed. 34, 1997.

DELEUZE, G. Diferença e repetição. Rio de Janeiro, Graal, 2006.

DEWEY, J. Pragmatismo e textos selecionados. São Paulo: Abril Cultural , 1974. (Os pensadores).

Pragmatismo e outros textos. São Paulo: Abril Cultural , 1979. (Os pensadores).

Vida e educação. São Paulo: Edições Melhoramentos, 1975.

JAMES, W. Pragmatismo e outros textos. São Paulo: Abril Cultural, 1979. (Os pensadores).

Pragmatismo; textos selecionados. São Paulo: Abril Cultural, 1974. (Os pensadores).

LAPOUJADE, D. O Homem migrante. Conferência de 19 de setembro de 2009. Vídeo disponível em http://redehumanizasus.net/node/7974. Acesso em: 06/07/2010.

MOSTAFA, S.P. Um banho de empirismo: de Hume/Deleuze ao empirismo radical de Bruno Latour. InCID: R. Ci. Inf. e Doc., Ribeirão Preto, USP v. 1, n.1, p. 161-181, 2010.

MOSTAFA, S. P.; NOVA CRUZ, D. V. Para ler a filosofia de Gilles Deleuze e Félix Guattari. Campinas: Átomo, 2009.

RORTY, Richard. A filosofia e o espelho da natureza. Rio de Janeiro: Relume-Dumará, 1995

SEMETSKY, I. Deleuze, education and becoming. Rotterdam: Sense, 2006.

NOTAS

1 Rorty é autor notabilizado por ser o filósofo americano da contemporaneidade e por ser um dos seguidores e admiradores de John Dewey, com razoável penetração no Brasil, por ter seus livros divulgados em português.

2 Para maiores especificações sobre as características do Plano de Imanência em relação com os conceitos filosóficos, ver Mostafa e Nova Cruz, 2009, p. 55.

Artigo recebido em 12/12/2012

Aprovado em 01/04/2013 